\title{
Anger Management - Evaluation of a Cognitive-Behavioral Training Program for Table Tennis Players
}

\author{
by \\ Georges Steffgen ${ }^{1}$
}

\begin{abstract}
Based on a systematic review of the literature on anger and anger management in sport, there is evidence that anger might be dysfunctional, especially in sports requiring selective attention and fine-tuned motor skills. The research literature suggests that cognitive-behavioral intervention programs can be fruitful in helping athletes to understand and control dysfunctional anger. Therefore, the main goal of the present study was to evaluate the effectiveness of a brief training program for table tennis players in cognitive-behavioral anger management that aimed at changing their noneffective anger reactions. The sample comprised 18 young competitive table tennis players (age range from 16 to 22 years) divided randomly into a treatment $(n=10)$ and a control group $(n=8)$. A trained group leader instructed the treatment group. Six sessions were held over a period of two months. Cognitive-relaxation coping skills associated with social skills of subjects from the treatment group were compared to no-treatment controls. Psychological measurements (i.e., self-reports on anger) were applied before, during and after treatment as well as in a follow-up session. The oneyear follow-up session revealed that, in contrast to the control group, the treatment group showed a significant reduction in outwardly negative anger expression as well as anger reactions specific to table tennis. Despite limitations inherent in the research design, the training program was deemed effective.
\end{abstract}

Key words: anger management, evaluation, training program, table tennis.

\section{Introduction}

\section{Anger in sport}

Novaco (1986) considers anger as an affective stress reaction which occurs after frustration. In this view, anger as an emotional state is a consequence of experienced physiological arousal and its cognitive interpretation. Thus, anger as a multidimensional construct, is associated with cognitive distortions (e.g., misappraisals and attributions of blame), physiological changes (e.g., hypertension) and behavioral reactions (e.g., facial expressions, verbal/behavioural anger expression strategies; Kassinove and Sukhodolsky, 1995). Anger is not only an emotional state, varying across time, situation and intensity, but also a stable personality trait reflecting a person's tendency to experience anger frequently or intensely (Spielberger et al., 1995).

Anger is a frequent emotion in sport (Campo et al., 2012). Athletes involved in physical contact sports often interpret their competitive anger as beneficial to sports performance (Robazza and Bortoli, 2007). They regard anger as helpful to energize behaviour (Robazza et al., 2006). However, table-tennis players (as an example for a non-physical contact sport) perceived ongoing, recurrent anger as debilitating, due to the fact that a surplus of energy is taxing in terms of self- control and may interfere with optimal performance (Martinent et

1 - University of Luxembourg, Institute for Health and Behaviour. 
al., 2012). Although some athletes subjectively experience anger as facilitating, there is evidence that anger can instead become dysfunctional, especially in sports requiring sustained focus, effort and attention over longer periods of time (Hanin, 2000).

Table tennis players are confronted with multiple critical situations that instigate annoyance, frustration and anger. It is assumed that interfering cognitions provoke this emotional tension (Krohne and Hindel, 2000). Therefore, table tennis players should try to reduce the negative impact of anger-specific interfering cognitions and develop an efficient emotional coping behavior instead (Krohne and Hindel, 2000). Since maladaptive anger experience and expression might create problems to athletes, they could profit from strengthening their ability to self-regulate their emotions in accordance with specific task requirements (Abrams, 2010; Isberg, 2000).

Anger treatment

Prototypical anger treatment programs start at three potential change levels of anger experience and expression (Steffgen and Pfetsch, 2007):

- Modification of physiological arousal: this includes systematic desensitization and relaxation treatment intended to reduce physiological arousal associated with anger and aiming to prevent unpleasant feelings and unfavorable behaviour (Dahlen and Deffenbacher, 2001).

- Modification of cognitive processes: this is based on cognitive treatments that are intended to modify cognitive processes such as hostile appraisals and attributions, irrational beliefs and inflammatory thinking (Ellis and Dryden, 2007). Alternative, more functional cognitions are developed and rehearsed. The experience of anger will thus be reduced so that anger intensity will remain at a level that allows adaptive behavior. In consequence, the expression of anger will be also changed.

- Modification of behavior (social interaction): social skills training is a common approach to anger treatment. In order to arrange interpersonal communication appropriately, the procedures in this area are based on the assumption that some people have social deficits. Hence, anger feelings cannot be expressed in a socially appropriate way, e.g., resistance to provocations or violations of justified requirements without hurting the feelings of others (Deffenbacher et al., 2002). Social skills training teaches individuals appropriate skills for handling anger in social situations.

Hence, multi-component approaches are used, in which changes are intended on every one of the three regulation levels: psychophysiological processes, cognitive processes and social interaction processes (Deffenbacher, 2011; Steffgen, 2014).

Above and beyond multiple single studies in which the effectiveness of individual programs was evaluated, particularly cumulative metaanalyses on the effectiveness of anger treatments permit more robust and general conclusions (DiGuiseppe and Tafrate, 2003, 2007; Steffgen, 2014). Accordingly, meta-analytic reviews show that most of the research focuses on cognitive and behavioural interventions resulting in medium to large effect sizes in anger reduction. The use of multi-component procedures has especially demonstrated promise as an appropriate proceeding for anger interventions (Steffgen and Pfetsch, 2007). All in all, a treatment package of anger should include the following components: addressing motivation, cultivating the therapeutic alliance, managing physiological arousal, fostering cognitive change, implementing behavioral change, providing environmental supports for change, teaching relapse-prevention skills, initiating restitution and reintegration (DiGuiseppe, 1999).

Nevertheless, little research has yet focused on evaluating effective methods of controlling anger in sports (Brunelle et al., 1999). Therefore, the current study analyzed the effectiveness of cognitive-behavioral anger management training for table tennis players. In the following, we focused on the evaluation of training in terms of effectiveness in reducing maladaptive anger in table tennis over time.

\section{Material and Methods}

\section{Participants}

Participants were 18 competitive table 
tennis players from the Luxembourg national team with no known specific anger problems. Participants were randomly assigned to conditions for the cognitive-behavioral treatment $(\mathrm{n}=10)$ and for the control condition $(\mathrm{n}=8)$. Participants in the treatment group were in average 16.6 years old $(\mathrm{SD}=2.7$ years), had 7.1 years of competition experience $(\mathrm{SD}=3.4)$ and 11.6 training hours per week $(\mathrm{SD}=1.7)$. Control group participants did not differ from the treatment group (mean age $=17.4, \mathrm{SD}=2.6 ; 7.6$ years of competition experience, $\mathrm{SD}=2.0$; and 11.5 training hours per week; $\mathrm{SD}=2.1$ ).

\section{Treatment - Anger Management Training}

In the present study we constructed an anger intervention ( 6 sessions of $120 \mathrm{~min}$ ) that emphasized cognitive-relaxation skills as well as social problem solving skills. This intervention was compared with a no-treatment control condition. Due to organizational requirements and time consuming extensive technical training of the young athletes, our program of anger intervention was limited to six sessions.

Cognitive relaxation coping training (CRCT): the first three sessions of $120 \mathrm{~min}$ were devoted to a cognitive-relaxation coping rationale and were based on training of the following relaxation coping skills: relaxation without tension, breathing-cued relaxation, cue-controlled relaxation and relaxation imagery. Also the identification as well as cognitive restructuring of anger-related self-talk were introduced and appropriate cognitive coping skills were developed. Subjects visualized personal sport specific anger scenes, experienced anger arousal and then used cognitive and relaxation coping skills to lower the level of anger. Homework focused on (cognitive) self-monitoring, relaxation practice and in vivo applications as well as mental training by visualization was given (Deffenbacher et al., 1987, 2002).

Social problem solving training (SPST): the second part of the intervention (again three sessions of $120 \mathrm{~min}$ ) was based on the social problem solving model (D'Zurilla and Nezu, 2010). Subjects learned to understand anger problems and find effective "solutions" or ways of coping with them. Four major skills were developed and trained: a) problem definition and formulation, $b$ ) generation of alternative solutions, c) decision making, and d) solution implementation and verification. Communication skills of behavioral, situational, impact and feeling descriptions were trained in feedback situations. Homework focused on using the social problem solving schema and communication skills.

Control participants knew that they would not receive any form of actual treatment.

\section{Measures}

\section{General trait measures}

Trait Anger Expression Inventory (TAXI): the Trait Anger Expression Inventory (Spielberger, 1988; German version) is a 42 -item questionnaire that provides a measure of the disposition towards anger as a personality trait (trait anger; 12 items) and three different forms of expression of anger (anger-in, anger-out, anger control; always 10 items). Participants rate themselves on a four-point Likert-type frequency scale: "almost never", "sometimes", "often" to "almost always". Internal consistency reliability ranges from .81 to .85 .

Trait Anxiety Scale (TAI): a measure of general anxiety was included to assess treatment generalization to non-targeted anxiety. General anxiety was evaluated by the trait anxiety scale (12 items; Spielberger et al., 1983; German version). Participants rate themselves on a fourpoint Likert-type frequency scale: "almost never", "sometimes", "often" to "almost always". Internal consistency reliability ranges from .87 to .91 .

Emotional tension - Anger and Agitation (TT anger): a sport specific measure was included to assess interfering cognitions designated as "emotional tension". This measure distinguishes between thoughts that comprise anger because one has missed an opportunity to win points (concrete situations), annoyance at one's own poor performance (entire match) or anger toward the opponent. (12 items; subscale Emotional extension - anger and agitation of the Cognitive Interference Test - Table tennis; CIF-TT, from Krohne and Hindel, 2000). Participants rate themselves on a four-point Likert-type frequency scale: "almost never", "sometimes", "often" to "almost always". Internal consistency reliability is .77 .

Situation-reaction measures

Situation Reaction Anger Expression Inventory (SRAEI): the SRAEI is a new purpose-constructed self-report scale consisting of 18 general anger provoking events (vignettes). For each vignette 
we presented a series of four items asking the participants to estimate their emotional reactions (state anger, anger-in, anger-out, anger control). Through this vignettes we measured situation specific anger, anger-in, anger-out, anger control (4 subscales; 18 items each). Participants rate their reactions on a four-point Likert-type response scale: "not at all" to "very much".

Situation Reaction Anger Expression Inventory specific to table tennis (SRAEI-TT): the SRAEITT presents a modified table tennis-specific version of the SRAEI. It consists of 7 anger provoking events in table tennis (vignettes). For each vignette we presented a series of four items asking the participants to estimate their emotional reactions (state anger, anger-in, anger-out, anger control). Through this vignettes we assessed situation specific anger, anger-in, anger-out, anger control (4 subscales; 7 items each). Participants rated themselves on a four-point Likert-type response scale: "not at all" to "very much".

\section{Procedure}

Data collection was scheduled at four times: Time 1 ('pre-test') immediately prior to the intervention; Time 2 ('inter-test') immediately after the first part, i.e., cognitive-relaxation coping training; Time 3 ('post-test') immediately after training; Time 4 ('follow up-test') one year after the intervention. The questionnaires were administered to the participants by the author in order to help with individual questions. Situationreaction measures were only employed pre- and post-treatment.

\section{Data-Analysis}

Due to the small number of participants, we used nonparametric tests (Wilcoxon for dependent samples, Mann-Whitney $U$ for independent samples).

\section{Results}

\section{Pre-treatment comparison}

Treatment and control groups had approximately similar levels of anxiety, anger and anger expression prior to treatment. The MannWhitney $U$ test on the pre-treatment data revealed no significant effects. Thus, groups did not differ considering pre-treatment individual differences (Tables 1 and 2). The Spearman correlation showed that all dependent measures were significantly inter-correlated with the exception of the anger-in variables. Anger-in (general trait), anger-in (situation reaction) and TT-anger in were the only variables correlated to each other (between .45 and .63).

Comparison between and within the treatment and control group

A comparison between treatment and control groups indicated that table tennis players of the treatment group presented significantly lower levels of anxiety and anger-out at inter-test time 2. They also showed a lower level of specific table tennis anger (general trait as well as situation reactions measure) after the intervention (Tables 3 and 4).

Significant treatment effects were also found considering different variables within the treatment group. Comparing pre-post measures within the treatment group, they showed a decrease of general and sport specific anger-out expression and sport specific anger as well as an increase of general and sport specific anger control (Table 3).

The data retained for athletes $(n=17)$ in the 12-month follow up are presented in Table 4 . The Mann-Whitney $U$ test of the difference value between two measurement times (pre-follow up) revealed significant between-group differences for anger-out and for specific table tennis anger (measure: general trait).

\section{Discussion}

The present study supports earlier findings on the effectiveness of cognitive behavior training on anger reduction (Del Vecchio and O'Leary, 2004) and provides significant information about the efficacy of such training in the field of racquet sports.

The results indicate that the training program was effective for table tennis anger in particular and anger-out reductions in general. These effects were still present at a 12-month follow-up. The results of the present sport-specific training program were similar to those found by Deffenbacher (2011) showing that cognitive behavior training reduced trait anger and angerout behavior for different target groups. Especially in table tennis, which requires sustained focus and attention, a surplus of angerrelated energy or anger-out behavior will be dysfunctional and counterproductive (Krohne and Hindel, 2000). 
Table 1

General trait measures, data presented as mean and standard deviation

\begin{tabular}{|c|c|c|c|c|c|c|}
\hline \multirow[b]{2}{*}{ Scale } & \multirow[b]{2}{*}{ Time } & \multicolumn{2}{|c|}{ Treatment group } & \multicolumn{2}{|c|}{ Control group } & \multirow{2}{*}{$\begin{array}{c}\text { Pre-treatment } \\
\text { U-Test Z }\end{array}$} \\
\hline & & M & SD & M & $\mathrm{SD}$ & \\
\hline \multirow[t]{4}{*}{ Anxiety } & Pre & 25.40 & 3.47 & 24.25 & 5.65 & -.22 \\
\hline & Inter & 22.80 & 4.21 & 26.13 & 5.74 & \\
\hline & Post & 22.78 & 3.46 & 24.29 & 5.82 & \\
\hline & Foll & 25.50 & 4.55 & 24.57 & 4.58 & \\
\hline \multirow[t]{4}{*}{ Anger } & Pre & 24.90 & 5.81 & 25.75 & 6.14 & -.27 \\
\hline & Inter & 24.10 & 4.48 & 27.13 & 5.46 & \\
\hline & Post & 23.22 & 3.73 & 25.86 & 6.47 & \\
\hline & Foll & 24.00 & 4.24 & 24.86 & 4.85 & \\
\hline \multirow[t]{4}{*}{ Anger in } & Pre & 22.40 & 4.40 & 19.63 & 5.63 & -1.52 \\
\hline & Inter & 19.40 & 4.45 & 20.38 & 6.07 & \\
\hline & Post & 22.11 & 4.20 & 20.14 & 5.01 & \\
\hline & Foll & 22.30 & 4.81 & 23.71 & 3.90 & \\
\hline \multirow[t]{4}{*}{ Anger out } & Pre & 16.60 & 3.60 & 17.63 & 4.31 & -.81 \\
\hline & Inter & 16.30 & 2.98 & 20.63 & 5.13 & \\
\hline & Post & 16.00 & 4.21 & 18.86 & 3.76 & \\
\hline & Foll & 16.30 & 2.67 & 21.29 & 5.41 & \\
\hline \multirow[t]{4}{*}{ Anger control } & Pre & 29.10 & 5.65 & 25.00 & 5.01 & -1.35 \\
\hline & Inter & 29.50 & 3.24 & 24.13 & 3.94 & \\
\hline & Post & 29.89 & 3.41 & 24.43 & 3.60 & \\
\hline & Foll & 28.60 & 4.20 & 22.86 & 5.18 & \\
\hline \multirow[t]{4}{*}{ TT anger } & Pre & 26.60 & 5.02 & 24.38 & 6.99 & -.85 \\
\hline & Inter & 27.10 & 5.93 & 26.50 & 4.47 & \\
\hline & Post & 24.78 & 5.56 & 26.57 & 5.94 & \\
\hline & Foll & 24.30 & 6.79 & 26.57 & 5.59 & \\
\hline
\end{tabular}

Table 2

Situation reaction measures, data presented as mean and standard deviation

\begin{tabular}{|c|c|c|c|c|c|c|}
\hline \multirow[b]{2}{*}{ Scale } & \multirow[b]{2}{*}{ Time } & \multicolumn{2}{|c|}{ Treatment group } & \multicolumn{2}{|c|}{ Control group } & \multirow{2}{*}{$\begin{array}{l}\text { pre-treatment } \\
\text { U-Test Z }\end{array}$} \\
\hline & & $\mathrm{M}$ & SD & M & SD & \\
\hline \multirow[t]{2}{*}{ Anger } & Pre & 50.40 & 6.31 & 51.88 & 9.75 & -.76 \\
\hline & Post & 48.89 & 6.07 & 53.71 & 11.01 & \\
\hline \multirow{2}{*}{ Anger in } & Pre & 40.20 & 7.38 & 35.13 & 9.88 & -1.38 \\
\hline & Post & 37.67 & 10.15 & 35.29 & 6.42 & \\
\hline \multirow[t]{2}{*}{ Anger out } & Pre & 36.90 & 8.33 & 31.25 & 6.61 & -1.56 \\
\hline & Post & 31.67 & 7.70 & 32.00 & 8.60 & \\
\hline \multirow[t]{2}{*}{ Anger control } & Pre & 46.30 & 9.19 & 43.63 & 8.43 & -.71 \\
\hline & Post & 51.50 & 7.25 & 44.00 & 5.39 & \\
\hline \multirow[t]{2}{*}{ TT-Anger } & Pre & 19.10 & 3.48 & 19.00 & 3.55 & -.32 \\
\hline & Post & 17.33 & 3.32 & 19.71 & 3.35 & \\
\hline \multirow[t]{2}{*}{ TT-Anger in } & Pre & 18.70 & 3.06 & 18.13 & 4.22 & -.13 \\
\hline & Post & 16.89 & 4.81 & 18.57 & 4.47 & \\
\hline \multirow[t]{2}{*}{ TT-Anger out } & Pre & 13.20 & 4.54 & 10.00 & 1.20 & -1.17 \\
\hline & Post & 10.22 & 3.53 & 9.71 & 2.50 & \\
\hline \multirow[t]{2}{*}{ TT-Ang control } & Pre & 18.90 & 3.07 & 19.88 & 2.70 & -.63 \\
\hline & Post & 21.56 & 3.97 & 20.00 & 3.37 & \\
\hline
\end{tabular}




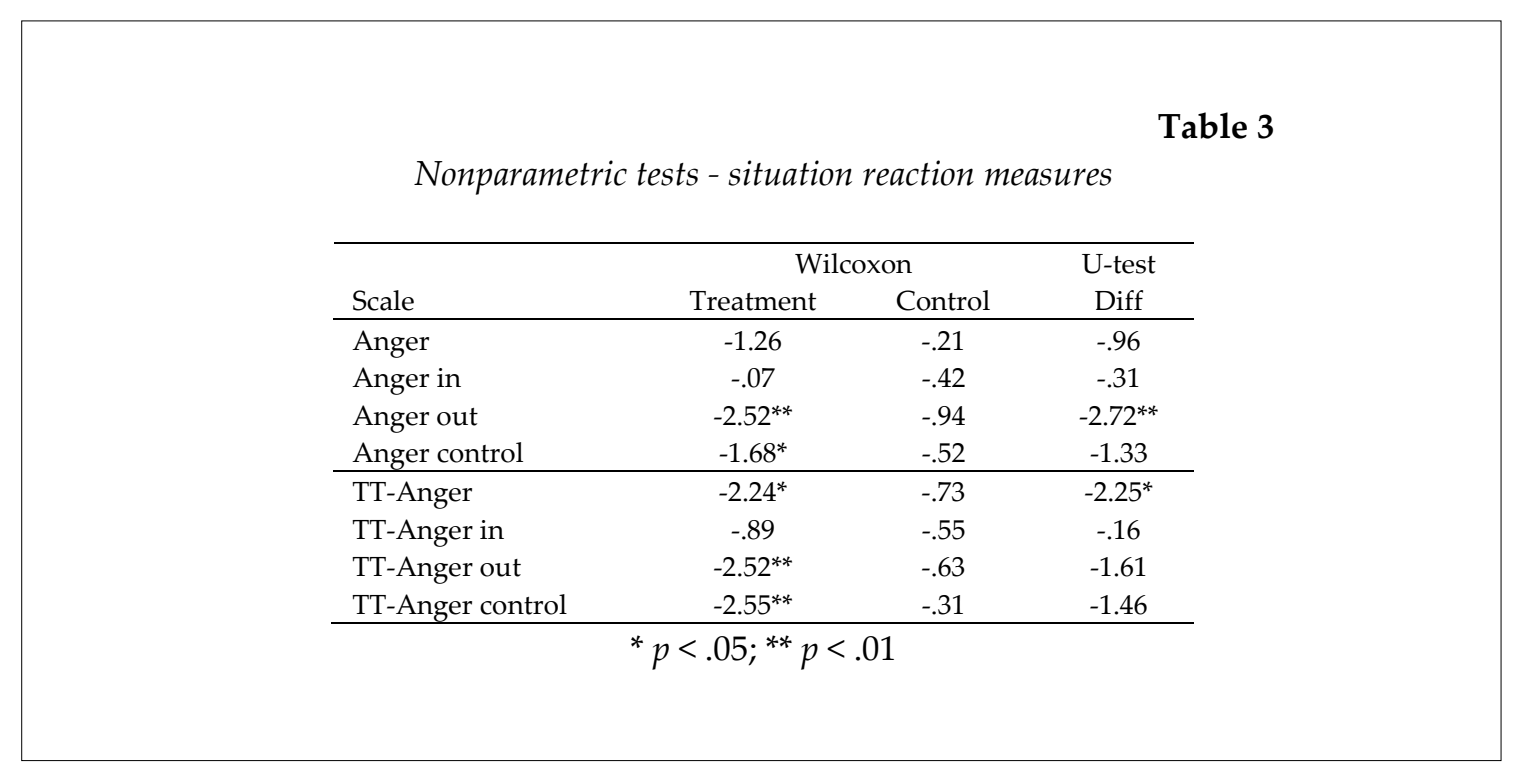

\begin{tabular}{|c|c|c|c|c|c|}
\hline \multicolumn{6}{|c|}{ Table 4} \\
\hline Scale & $\begin{array}{c}\text { time } \\
\text { difference }\end{array}$ & $\begin{array}{c}\text { U-Test } \\
\text { Difference }\end{array}$ & Scale & time & $\begin{array}{c}\text { U-Test } \\
\text { Difference }\end{array}$ \\
\hline \multirow{3}{*}{ Anxiety } & Pre-Inter & $-2.23^{*}$ & Anxiety & Pre-Foll & -.44 \\
\hline & Inter-Post & -1.45 & & Inter-Foll & -1.49 \\
\hline & Pre-Post & -1.22 & & Post-Foll & $-1.68^{*}$ \\
\hline \multirow[t]{3}{*}{ Anger } & Pre-Inter & 1.30 & Anger & Pre-Foll & .00 \\
\hline & Inter-Post & -.16 & & Inter-Foll & -1.23 \\
\hline & Pre-Post & -.32 & & Post-Foll & $-1.72^{*}$ \\
\hline \multirow[t]{3}{*}{ Anger in } & Pre-Inter & -1.33 & Anger in & Pre-Foll & -1.18 \\
\hline & Inter-Post & -.69 & & Inter-Foll & .00 \\
\hline & Pre-Post & -.54 & & Post-Foll & -.65 \\
\hline \multirow[t]{3}{*}{ Anger out } & Pre-Inter & $-1.71^{*}$ & Anger out & Pre-Foll & $-1.81^{*}$ \\
\hline & Inter-Post & -1.34 & & Inter-Foll & -.10 \\
\hline & Pre-Post & -1.04 & & Post-Foll & -1.13 \\
\hline \multirow[t]{3}{*}{ Anger control } & Pre-Inter & -.63 & Anger control & Pre-Foll & -1.28 \\
\hline & Inter-Post & -.38 & & Inter-Foll & -.25 \\
\hline & Pre-Post & -.85 & & Post-Foll & -.42 \\
\hline \multirow[t]{3}{*}{ TT anger } & Pre-Inter & -.90 & TT anger & Pre-Foll & $-1.82^{*}$ \\
\hline & Inter-Post & $-1.65^{*}$ & & Inter-Foll & -1.63 \\
\hline & Pre-Post & $-1.65^{*}$ & & Post-Foll & -.17 \\
\hline \multicolumn{6}{|c|}{${ }^{*} p<.05$} \\
\hline
\end{tabular}

In their meta-analysis, Candelaria et al. (2012) found no significant intervention effect of treatment length or exact timing of intervention sessions on anger management. In this regard, the present study substantiates that even six sessions can be sufficient to produce sustainable effects.
Brief interventions are superior in terms of both cost-effectiveness and short-term effects. Therefore, this training program should not only be applied in racquet sports, but also in other sports.

Using combined interventions in sport can 
be also beneficial for daily-life. It can reduce dailylife anger by targeting multiple aspects of dysfunctional anger. Moreover, it can reduce anger-out in daily anger provoking situations by transferring anger management skills.

Although the study provides new valuable input to research on anger management in sports, it is not without limitations. First of all, the small sample size has to be considered. Future research should be conducted with more participants.

Participants were also from a single national team from a European country. With athletes from different (sport) cultures the generalizability of the study will be strengthened. Also, culturally sensitive issues have to be identified and considered. The assessment of more personal characteristics would help explain why people differ in terms of their positive response to treatment.

Due to the serial presentation of the two different parts of the intervention, it is not possible to interpret the effectiveness of each part independently. At least a second training group with reverse order applied is needed.

Furthermore, the group leader developed, assessed and analyzed the effects of the training program, which calls for a division of roles to rule out person effects.

Notably, real performance indicators in table tennis should be helpful to confirm the findings under real playing conditions (e.g., from video observations). Moreover, evaluating the effectiveness of anger and anger expression is still difficult in sports. Different functions and intentions of anger in sports highlight the fact that a generally valid evaluation of the (in)effectiveness of anger expressions, independent of specific sport forms or specific situational goals within specific sport forms (e.g., particular training goals), is hardly possible.

All in all, the treatment was shown to raise the self-awareness of athletes, so they learnt to consider triggers, experiences, expression and consequences of their anger. However, group leaders need to ensure that the approach is consistent with the athletes' expectations and values. They also need to evaluate and monitor the procedures for evidence-based practice (Saini, 2009).

In summary, the results of this study await replication in studies using different sports and multiple program training as well as other behavioral measures that do not rely on selfreports. The present short-time training led to long-term anger reduction in table tennis players. Moreover, these effects were found to be as robust as those obtained in shorter follow-ups (Deffenbacher et al., 2002; DiGuiseppe, 1999). However, future research on anger management in different sports is needed for more in-depth analyses of the predictors and moderators of anger treatment outcomes.

\section{References}

Abrams M. Anger management in sport: Understanding and controlling violence in athletes. Champaign, IL: Human Kinetics; 2010

Brunelle JP, Janelle CM, Tennant LK. Controlling competitive anger among soccer players. J Appl Sport Psychol, 1999; 20: 73-87

Candelaria AM, Fedewa AL, Ahn S. The effects of anger management on children's social and emotional outcomes: A meta-analysis. School Psychol Inter, 2012; 33: 596-614

Campo M, Mellalieu S, Ferrand C, Martinent G, Rosnet E. Emotions in team contact sports: A systematic review. Sport Psychol, 2012; 26: 62-97

Dahlen ER, Deffenbacher JL. Anger management. In Empirically supported cognitive therapies: Current and future applications. New York, NY: Springer, 163-181; 2001

Del Vecchio T, O'Leary KD. Effectiveness of anger treatments for specific anger problems: A meta-analytic review. Clin Psychol Rev, 2004; 24: 15-34

Deffenbacher JL. Cognitive-behavioral conceptualization and treatment of anger. Cog Behav Pract, 2011; 18: $212-221$ 
Deffenbacher JL, Oetting ER, DiGuiseppe R. Principles of empirically supported interventions applied to anger management. Counsel Psychol, 2002; 30(2): 262-280

Deffenbacher JL, Story DA, Stark RS, Hogg JA, Brandon AD. Cognitive-relaxation and social skills interventions in the treatment of general anger. J Counsel Psychol, 1987; 34: 171-176

DiGuiseppe R. End Piece: Reflections on the treatment of anger. J Clin Psychol, 1999; 55(3): 365-379

DiGuiseppe R, Tafrate RC. Anger treatments for adults: A meta-analytic review. Clin Psychol: Sci Pract, 2003; 10: $70-84$

DiGiuseppe R, Tafrate RC. Understanding anger disorders. New York: Oxford University Press; 2007

D'Zurilla TJ, Nezu AM. Problem solving therapy. In Handbook of cognitive behavioral therapies. New York, NY: The Guilford Press, 197-225; 2010

Ellis A, Dryden W. The practice of rational emotive behavior therapy. New York: Springer; 2007

Hanin YL. Emotions in sport. Champaign, IL: Human Kinetics; 2000

Isberg L. Anger, aggressive behavior, and athletic performance. In Emotions in sport. Champaign, IL: Human Kinetics, 113-134; 2000

Kassinove H, Sukhodolsky DG. Anger disorders: Basic science and practice issues. In Anger disorders: Definition, diagnosis, and treatment. Washington, DC: Taylor and Francis, 1-26; 1995

Krohne HW, Hindel C. Anxiety, cognitive interference, and sports performance: The cognitive-interference test - table tennis. Anx Stress Cop: Intern J, 2000; 13: 27-52

Martinent G, Campo M, Ferrand C. A descriptive study of emotional process during competition: Nature, frequency, direction, duration and co-occurrence of discrete emotions. Psychol Sport Exer, 2012; 13: 142151

Novaco RW. Anger as a clinical and a social problem. In Advances in the study of aggression. Orlando, FL: Academic Press, 1-67; 1986

Robazza C, Bortoli L. Perceived impact of anger and anxiety on sporting performance in rugby players. Psychol Sport Exer, 2007; 8: 875-896

Robazza C, Bertollo M, Bortoli L. Frequency and direction of competitive anger in contact sports. J Sports Med Phys Fit, 2006; 46: 501-508

Saini M. A meta-analysis of the psychological treatment of anger: Developing guidelines for evidence-based practice. J Americ Acad Psych Law Onl, 2009; 37: 473-488

Spielberger CD. 1988. STAXI. State Trait Anger Expression Inventory. Professional Manual. Tampa, FL: Psychological Assessment Resources; 1988

Spielberger CD, Gorsuch RL, Lushene RE. Manual for the State-Trait Anxiety Inventory (STAI). Palo Alto, CA: Consulting Psychologists Press; 1983

Spielberger CD, Reheiser EC, Sydeman SJ. Measuring the experience, expression, and control of anger. In Anger disorders: Definition, diagnosis, and treatment. Washington, DC: Taylor and Francis, 49-67; 1995

Steffgen G. Anger. In Encyclopedia of Quality of Life and Well-Being. Berlin: Springer, 175-179; 2014

Steffgen G, Pfetsch J. Does anger treatment reduce aggressive behaviour? In Emotions and Aggressive Behavior. Göttingen: Hogrefe, 92-111; 2007

\section{Corresponding author:}

\section{Georges Steffgen}

University of Luxembourg, Belval Campus, Institute for Health and Behavior

11, Porte des Sciences, L-4366 Esch-sur Alzette. Luxembourg

Phone: (00)352 466644 6644,

E-mail: georges.steffgen@uni.lu 